\title{
EL PRINCIPIO DE LA REPARACIÓN DEL DAÑO AMBIENTAL EN EL DERECHO INTERNACIONAL PÚBLICO. UNA APROXIMACIÓN A SU RECEPCIÓN POR PARTE DEL DERECHO MEXICANO
}

\author{
Tania GARCÍA LÓPEZ*
}

\begin{abstract}
RESUMEN: El presente estudio analiza la cuestión de la reparación del daño ambiental como principio jurídico. El principio surge en el ámbito del derecho internacional público y posteriormente es recibido por los distintos ordenamientos jurídicos nacionales, entre ellos el mexicano. Se estudia el principio tanto desde la óptica del derecho internacional público general como particular. Asimismo, se analiza el estado de la cuestión en la Unión Europea, para terminar con una revisión del principio en el ordenamiento jurídico mexicano. La reparación del daño ambiental en México se aborda en el presente artículo tanto dentro del derecho civil como del penal y el administrativo.
\end{abstract}

ABSTRACT: The present study analyzes the compensation of environmental damage as a legal principle. The principle arises first within the international public sphere and then is embraced by different national legal systems, such as the Mexican one. The principle is studied from the public international law point of view, both, in its general and specific parts as well as within the EU and the Mexican context. The environmental damage compensation in the case of Mexico includes revision from such areas as Civil, Criminal and Administrative Law.

RÉSUMÉ: La présente étude analyse la question de la réparation du dommage causé à l'environnement comme principe juridique. Ce principe est apparu dans le domaine du droit international public avant d'être intégré par d'autres législations juridiques nationales, dont la législation mexicaine. Ce principe est étudié sous l'angle du droit international public, de manière générale ainsi que sur des points particuliers. Par exemple, ou en est-on du débat au sein de l'Union européenne pour conclure avec le Mexique une révision du principe dans l'ordre juridique mexicain. La réparation du dommage environnemental au Mexique est abordée étudié tant en droit civil qu'en en matière pénale et administrative.

* Directora de Posgrado y Extensión Universitaria. Universidad Anáhuac de Xalapa. 
SUMARIO: I. Introducción. II. El principio de la reparación del daño ambiental en el derecho internacional público. III. El estado de la cuestión en la Unión Europea. IV. La reparación del daño ambiental en el ordenamiento jurídico mexicano.

V. Conclusiones. VI. Bibliografía.

\section{INTRODUCCIÓN}

Los daños ambientales son de difícil reparación, y en algunas ocasiones, por ejemplo si se trata de la pérdida de especies, son irreparables. Sin embargo, cuando nos encontramos con que el daño ambiental ya se ha producido, bien porque se ha actuado de forma ilícita, superando los límites máximos previstos en las normas jurídicas, o debido a que se ha producido un accidente, o por otras causas, el principio de la reparación del daño ambiental, conocido también como reparación in natura, exige que no quede a elección del ofendido la forma de reparación, sino que se prefiera esta opción en lugar de la tradicional indemnización.

Los daños ambientales son autónomos y diferentes de los daños personales, por lo que, en ocasiones, es posible que una conducta produzca, además de daños al ambiente, lesiones a particulares. En estos casos es necesario hacer una distinción, ya que la reparación de los elementos ambientales beneficia a toda la sociedad, mientras que la reparación de las lesiones a particulares podrá darse a través de indemnización, tomando en cuenta tanto el daño como el perjuicio (lucro cesante).

En este sentido, el Tribunal Supremo español establecía en 1989:

Cuanto se recoge en las disposiciones administrativas: Reglamento de Actividades Molestas, Insalubres, Nocivas y Peligrosas, Ley sobre Protección Ambiental, Decreto de 6 de febrero de 1975 sobre adopción de medidas protectoras, se está refiriendo a estados generales de perturbación del medio ambiente con graves situaciones para la población situada en determinadas zonas que por su generalidad están contemplando intereses públi$\cos$, lo que no puede equipararse a la lesión patrimonial por inmisiones dañosas en propiedades determinadas, cuyos titulares demandan el pertinente resarcimiento y el consiguiente remedio a la actividad ocasionadora del menoscabo, cuestiones éstas que son de exclusiva competencia de los tribunales del orden civil. ${ }^{1}$

1 Sentencia del Tribunal Supremo español del 16 de enero de 1989, Jurisprudencia sobre medio ambiente, Madrid, Ministerio de Medio Ambiente, 1996. 
En algunos casos, los límites máximos de contaminación previstos por las normas jurídicas, lo que se conoce como contaminación legal o lícita, no garantizan la inexistencia de daños al ambiente graves, ya que dichos estándares no siempre están correctamente fijados desde la perspectiva ambiental. ${ }^{2}$

En este sentido, el mismo Tribunal Supremo español ha reconocido responsabilidad civil por daños causados por emanaciones ajustadas a la normativa administrativa. ${ }^{3}$

La misma sentencia del Tribunal Supremo español, de 16 de enero de 1989 señala:

En verdad importa evitarse o aclararse el equívoco de creer... que porque a la administración y en relación a aquel interés público corresponda ordenar y controlar la adopción de medidas protectoras, se trata en todos sus aspectos de materia propia del derecho administrativo y ciertamente que le interesa en aquellos aspectos generales, pero independientemente, cuando afecta a derechos subjetivos privados pierde aquel carácter para entrar de plano en el campo del derecho civil... y que de incurrir en responsabilidad, se hará efectiva bajo el dictado de la legislación civil, sin olvidar que el acatamiento y observación de las normas administrativas no colocan al obligado al abrigo de la correspondiente acción civil de los perjudicados o interesados en orden a sus derechos subjetivos lesionados. ${ }^{4}$

Este principio se conoce también como restauración efectiva. El derecho ambiental tiene un carácter básicamente preventivo, que busca evitar el daño ambiental $\mathrm{y}$, de acuerdo al principio quien contamina paga, carga el coste económico de esa prevención al potencial contaminador, pero si el daño se ha producido, es necesario repararlo.

\section{EL PRINCIPIO DE LA REPARACIÓN DEL DAÑO AMBIENTAL EN EL DERECHO INTERNACIONAL PÚBLICO}

En el ámbito del derecho internacional público el daño ambiental puede producirse como consecuencia de la contravención de una norma

2 Cfr. Loperena Rota, Demetrio, Los principios del derecho ambiental, Madrid, Civitas, 1998, p. 95.

3 Idem.

4 Sentencia del Tribunal Supremo español del 16 de enero de 1989, op. cit., nota 1. 
jurídica internacional o bien sin que se produzca un ilícito. En el primero de los supuestos es posible que la violación que cause el daño esté vulnerando una disposición contenida en un tratado internacional que prevea un sistema específico de responsabilidad, o bien que el Estado lesionado invoque las normas tradicionales relativas a la responsabilidad internacional porque dicha violación no conlleve un tipo específico de reparación. Además, es posible que se produzca un daño sin infringir ninguna norma jurídica internacional. En este último supuesto se habla normalmente de la responsabilidad del Estado por actos no prohibidos por el derecho internacional.

La Declaración de Estocolmo ${ }^{5}$ destacaba en 1972 la necesidad de que los Estados siguiesen desarrollando el derecho internacional en lo referente a la responsabilidad y a la indemnización a las víctimas de la contaminación y otros daños ambientales. ${ }^{6}$

Por su parte, el principio 10 de la Declaración de Río ${ }^{7}$ señala: "Deberá proporcionarse acceso efectivo a los procedimientos judiciales y administrativos, entre otros el resarcimiento de daños y los recursos pertinentes".

El principio 13 añade: "Los Estados deberán cooperar asimismo de manera expedita y más decidida en la elaboración de nuevas leyes internacionales sobre responsabilidad e indemnización por los efectos adversos de los daños ambientales causados por las actividades realizadas dentro de su jurisdicción, bajo su control, o en zonas situadas fuera de toda jurisdicción". ${ }^{8}$

Más adelante, en la Conferencia de Johannesburgo ${ }^{9}$ se abona esta postura al reconocerse que la reparación de los daños ambientales sigue sin ser la tónica imperante en el derecho internacional del medio ambiente.

5 Declaración final de la Conferencia de Naciones Unidas sobre el Medio Humano, Estocolmo, Suecia, 16 de junio de 1972, en Torres Ugena, Nila (comp.), Textos normativos de derecho internacional público, 5a. ed., Madrid, Civitas, 1996.

6 Ibidem, principio 22.

7 Declaración final de la Conferencia de Naciones Unidas sobre Medio Ambiente y Desarrollo, Río de Janeiro, Brasil, 14 de junio de 1992, en Torres Ugena, Nila (comp.), op. cit., nota 5.

8 Idem.

9 Conferencia de Naciones Unidas sobre Desarrollo Sustentable, Johannesburgo, Sudáfrica, septiembre de 2002, http://www.un.org/esa/sustdev/documents/WSSD_POI_ PD/Spanish/WSSDsp_PD.htm. 


\section{La reparación del daño ambiental en el derecho internacional general}

Dentro de los principios generales del derecho internacional público se encuentra el que constituye la base del régimen de responsabilidad internacional por daños ambientales, a saber: "La violación de una obligación genera la obligación de reparar el daño que se produzca". ${ }^{10}$

Además, y ya en el ámbito específico del derecho internacional ambiental, existe el principio según el cual: "Los Estados tienen el deber de asegurar que sus actividades o las realizadas dentro de su jurisdicción o bajo su control no causen contaminación más allá de sus fronteras, en el medio ambiente de otros Estados o en áreas más allá de toda jurisdicción nacional". ${ }^{11}$

En el asunto del Trail Smelter de $1941^{12}$ ya se reconoció este principio cuando se afirmaba: según los principios del derecho internacional, ningún Estado tiene derecho a usar o permitir que se use su territorio de modo que se causen daños por humos en o al territorio de otro o a la propiedad de las personas que allí se encuentren, cuando se trata de un supuesto de consecuencias graves y el daño quede establecido por medio de una prueba clara y convincente.

En este mismo sentido, el principio 21 de la Declaración de Estocolmo ${ }^{13}$ dispone:

De conformidad con la Carta de las Naciones Unidas y con los principios del derecho internacional, los Estados tienen el derecho soberano de explotar sus propios recursos en aplicación de su propia política ambiental y la obligación de asegurar que las actividades que se lleven a cabo dentro

10 Declaración sobre los principios de derecho internacional referente a las relaciones de amistad y a la cooperación entre los Estados de conformidad con la Carta de las Naciones Unidas, Resolución 2625 (XV) de la Asamblea General de la Organización de las Naciones Unidas del 24 de octubre de 1970, en López Bassols, Hermilo, Derecho internacional público contemporáneo e instrumentos básicos, México, Porrúa, 2001.

11 Principio 22 de la Declaración de Naciones Unidas sobre Medio Ambiente y Desarrollo..., cit., nota 7.

12 Trail Smelter Case (United States of America vs. Canada), Award of March 11, 1941, Reports of International Arbitral Awards, United Nations, vol. III.

13 Declaración de Naciones Unidas sobre el Medio Humano..., cit., nota 5. 
de su jurisdicción o bajo su control no perjudiquen al medio de otros Estados o de zonas situadas fuera de toda jurisdicción nacional.

En 2001, la Comisión de Derecho Internacional presentó a la Asamblea General de las Naciones Unidas un Proyecto de Artículos sobre la Responsabilidad Internacional de los Estados por Hechos Internacionalmente Ilícitos. ${ }^{14}$

De conformidad con el artículo 10. del proyecto: "Todo hecho internacionalmente ilícito del Estado genera responsabilidad internacional".

Según el artículo 30: "El Estado responsable del hecho internacionalmente ilícito está obligado: a) A ponerle fin si ese hecho continúa, y b) A ofrecer seguridades y garantías de no repetición, si las circunstancias lo exigen".

Además, el artículo 31 añade: "1. El Estado responsable está obligado a reparar íntegramente el perjuicio causado por el hecho internacionalmente ilícito y 2. El perjuicio comprende todo daño, tanto material como moral, causado por el hecho internacionalmente ilícito del Estado".

La forma más pertinente de reparación, de acuerdo a la mayor parte de la doctrina y del propio Tribunal Internacional de Justicia (TIJ), es la restitutio in integrum, forma clásica de la consecuencia de un hecho internacionalmente ilícito que ha generado la responsabilidad internacional del Estado. En palabras del TIJ en el asunto de la fábrica Chorzow (1928), es una forma de resarcimiento en la que la reparación debe borrar, en la medida de lo posible, todas las consecuencias del acto ilícito y restablecer la situación que hubiera existido verosímilmente si dicho acto no hubiera sido cometido. ${ }^{15}$

En este sentido, el artículo 35 del proyecto citado dispone: El Estado responsable de un hecho internacionalmente ilícito está obligado a la restitución, es decir a restablecer la situación que existía antes de la comisión del hecho ilícito, siempre que y en la medida en que esta restitución: a) No sea materialmente imposible y $b$ ) No entrañe una carga totalmente desproporcionada con relación al beneficio que derivaría de la restitución en vez de la indemnización.

15 Rodríguez Carrión, Alejandro J., Lecciones de derecho internacional público, Madrid, Tecnos, 2002, p. 337. 
De acuerdo a lo anterior, podemos observar cómo el régimen tradicional de responsabilidad internacional se centra en la reparación del daño y sólo en el caso de que ésta no fuese posible en la indemnización. Esta última posibilidad presenta problemas cuando tratan de valorarse los daños ambientales, porque los elementos ambientales no suelen tener un valor de mercado al encontrarse, mucho de ellos, dentro de la categoría de bienes de dominio público.

Para la valoración económica de un daño ambiental, es necesario tomar en cuenta los valores de uso de ese bien y otros valores. Dentro de estos últimos, normalmente se suelen incluir valores estéticos o de recreación y valores inherentes (como fuente de protección de cuencas, por ejemplo, relevantes para el calentamiento del planeta).

Como señala Kiss:

In evaluating or measuring damages a great deal of uncertainty exists because the elements of the environment often are not viewed as having economic value when they remain outside the marketplace. For example, there may be wide divergences in valuing seabirds killed by an oil spill or the aesthetic value of a clean coastline. In other cases, damages may be estimated according, to accept case law from other fields, including such items as lowered property values due to pollution or lost business due to smoke or noise. ${ }^{16}$

Sin embargo, hay quienes afirman que con base en los principios generales del derecho, universalmente reconocidos por los países civilizados, el Estado culpable tiene la facultad de negarse a la restitución natural y suplirla con una indemnización de igual valor si la demanda de que se restablezca la situación anterior constituye un abuso del derecho. Este es el caso cuando se pide la restitución natural, a pesar de que se haya ofrecido una indemnización equivalente y que la vuelta al estado anterior haya de ocasionar gastos desproporcionados. ${ }^{17}$

Habitualmente se distingue entre daños al ambiente y daños a través del medio ambiente. Cuando hablamos de daños al ambiente nos referimos al daño ambiental per se, mientras que en el segundo supuesto nos

16 Kiss, Alexandre y Shelton, Dinah, International Environmental Law, Nueva York, Transnational Publishers, Inc., 1991, pp. 354 y ss.

17 Cfr. Verdross, Alfred, Derecho internacional público, Madrid, Biblioteca Jurídica Aguilar, 1976, p. 377. 
centramos básicamente en la responsabilidad civil tradicional: daños personales, patrimoniales y económicos. ${ }^{18}$

Si acudimos, entonces, al derecho internacional público general, la reparación del daño ambiental sería una exigencia y sólo se acudiría a la indemnización en caso de que no fuese posible aquélla. Sin embargo, el concepto tradicional de daño en derecho internacional público se estructura bajo la óptica de los daños personales, patrimoniales y económicos, lo cual no garantiza la protección del medio ambiente.

\section{La reparación del daño ambiental en el derecho internacional particular}

A través de tratados internacionales es posible prever la reparación del daño cuando un Estado incumple alguna de las disposiciones de dicho acuerdo.

El Convenio de Londres sobre la Prevención de la Contaminación del Mar por Vertimiento de Desechos y otras Materias ${ }^{19}$ dispone así, en su artículo 10, que de conformidad con los principios del derecho internacional relativos a la responsabilidad de los Estados por los daños causados al medio ambiente de otros Estados o cualquier otra zona del medio ambiente por el vertimiento de desechos y otras materias de cualquier clase, las partes contratantes se comprometen a elaborar procedimientos para la determinación de responsabilidades y el arreglo de controversias relacionadas con las operaciones de vertimiento.

Como podemos observar, las partes en dicho convenio se obligaron únicamente a desarrollar procedimientos para la evaluación de la responsabilidad, sin concretar nada en relación a las consecuencias de dicha responsabilidad.

En este mismo sentido, el Convenio para la Protección del Medio Marino en la Zona del Mar Báltico, ${ }^{20}$ establece en el artículo 17 que las partes contratantes se comprometen, tan pronto como sea posible, a desarrollar conjuntamente y a aceptar las reglas relativas a la responsabilidad

18 En este sentido, Fayette, Louise de la, "The concept of Environmental Damage in International Liability Regimes", en Bowman, Michael y Boyle, Alan, Environmental Damage in International and Comparative Law. Problems of Definition and Valuation, Oxford, Oxford University Press, 2002, pp. 181 y ss.

19 Adoptado en Londres en 1972, DOF del 16 de julio de 1975.

20 Adoptado en Helsinki el 22 de marzo de 1974, http://www.un.org/Depts/Treaty/. 
por el daño resultante de actos u omisiones en contravención de la presente convención, incluyendo, entre otras cosas, límites a la responsabilidad, criterios y procedimientos para la determinación de la responsabilidad y remedios disponibles.

El Convenio de Nairobi para la Protección, la Ordenación y el Desarrollo del Medio Marino y Costero de la Región de África Oriental ${ }^{21}$ en su artículo 15, sigue la misma línea al señalar que las partes contratantes cooperarán directamente, o en cooperación con organizaciones regionales o internacionales competentes con el objeto de elaborar y adoptar reglas y procedimientos apropiados que sean conformes con el derecho internacional, en la esfera de la responsabilidad y compensación del daño resultante por contaminación del área de la convención.

Sin embargo, hay otros tratados que sí se refieren a la reparación del daño ambiental. Así, el Convenio sobre Responsabilidad y Compensación de Daños Producidos por el Transporte de Sustancias Peligrosas y Nocivas por el Mar, adoptado en 1996,22 que todavía no ha entrado en vigor, prevé la compensación por las medidas preventivas necesarias para minimizar el daño ambiental.

El Convenio sobre Responsabilidad Civil por Daños Resultantes de Actividades Peligrosas para el Medio Ambiente de $1993^{23}$ define el daño ambiental como daño a personas y propiedades e incluye pérdidas económicas, así como lucro cesante ocasionado por el daño al medio ambiente. En lo que se refiere a la reparación, incluye la indemnización y la compensación ambiental y prevé medidas de remediación del daño.

Dentro de estas medidas se incluyen las acciones de restauración, cuya finalidad es recuperar el estado que guardaba el medio ambiente antes del daño y medidas compensatorias.

En el supuesto de que el daño al ambiente no pudiera ser reparado, por ejemplo por pérdida de especies, se deberán introducir en el área afectada, especies equivalentes, una vez que el área se haya limpiado. Se sigue, así, la solución adoptada al respecto por la legislación estadounidense.

21 Adoptado en Nairobi el 21 de junio de 1985, http://www.un.org/Depts/Treaty/.

22 Por la Organización Marítima Internacional, http://www.un.org/Depts/Treaty/.

23 Adoptado en Lugano por el Consejo de Europa el 21 de junio de 1993. 
El artículo 12 del Convenio de Basilea sobre Movimientos Transfronterizos de Desechos Peligrosos y su Eliminación ${ }^{24}$ en relación a este tema únicamente dispone que las partes cooperarán con miras a adoptar cuanto antes un protocolo que establecerá las normas y procedimientos apropiados en lo que se refiere a la responsabilidad y la indemnización de los daños resultantes del movimiento transfronterizo y la eliminación de los desechos peligrosos y otros desechos.

En diciembre de 1999 se adoptó por la Conferencia de las Partes, el Protocolo sobre Responsabilidad y Compensación por Daños Resultantes de los Movimientos Transfronterizos de Desechos Peligrosos y su disposición final. ${ }^{25}$

En el protocolo se define el concepto de daño ambiental, así como los de medidas de restauración y medidas preventivas.

De acuerdo a las definiciones del protocolo:

a) Por medidas de restauración se entiende cualquier tipo de medida razonable con el propósito de valorar, restablecer o restaurar los componentes del medio ambiente que han sido dañados o destruidos.

b) Por medidas preventivas se entiende cualquier medida razonable tomada por cualquier persona como respuesta a un incidente, para prevenir, minimizar o mitigar pérdidas o daños, o para limpiar el medio ambiente.

En el Convenio sobre la Reglamentación de las Actividades Relacionadas con los Recursos Minerales de la Antártida, de 1988, ${ }^{26}$ encontramos disposiciones más detalladas sobre la cuestión de la reparación del daño ambiental. El artículo 8 señala al respecto:

a) Un operador que lleve a cabo cualquier actividad sobre los recursos minerales antárticos tomará todos los pasos necesarios y la acción de respuesta oportuna, incluyendo medidas de prevención, contención, limpieza y remoción, si la actividad resulta o amenaza resultar en daño al medio ambiente antártico o a los ecosistemas dependientes o asociados.

b) Un operador tendrá responsabilidad estricta por:

1) El daño al medio ambiente antártico o a los ecosistemas dependientes o asociados generado por sus actividades sobre los recursos mi-

24 Adoptado en Basilea el 23 de marzo de 1989, http://www.un.org/Depts/Treaty/.

25 Protocolo del Convenio de Basilea de 1989, adoptado en 1999, http://www.un. org/Depts/Treaty/.

26 Adoptado en Wellington el 2 de junio de 1988, http://www.un.org/Depts/Treaty/. 
nerales antárticos, incluyendo el pago en el caso de que no haya restauración al status quo ante.

2) El reembolso de los costos razonables incurridos por quien sea en relación con la acción de respuesta necesaria, incluyendo medidas de prevención, contención, limpieza y remoción, y la acción tomada para restaurar el status quo ante donde se llevaron a cabo las actividades sobre los recursos minerales antárticos por ese operador y que resultaron en, o amenacen resultar en, un daño al medio ambiente de la Antártida o los ecosistemas dependientes o asociados.

El Convenio de Naciones Unidas sobre Derecho del Mar de 1982,27 por su parte, afirma en el artículo 235: “2. Los Estados asegurarán que sus sistemas jurídicos ofrezcan recursos que permitan la pronta y adecuada indemnización u otra reparación de los daños causados por la contaminación del medio marino por personas naturales o jurídicas bajo su jurisdicción".

La mayoría de las disposiciones analizadas, contenidas en acuerdos internacionales, se refieren básicamente a la necesidad de regular lo referente al establecimiento de normas y procedimientos relativos a la responsabilidad de los Estados y las consecuencias de dicha responsabilidad. No establecen claramente la necesidad de la reparación de los daños ambientales.

Es algo unánimemente aceptado que estos temas han encontrado especiales dificultades para su regulación por el ordenamiento jurídico internacional debido a la reticencia de los Estados a aceptar su responsabilidad internacional y las consecuencias de ésta. Por ello, como señala Juste Ruiz, "los textos internacionales que formulan el principio de responsabilidad y reparación de daños ambientales lo hacen en un tono de lege ferenda". ${ }^{28}$

En términos generales, un régimen de responsabilidad por daños ambientales tendría que tender a conseguir los siguientes objetivos: a) Desalentar las actividades peligrosas, b) Fomentar la reparación del daño ambiental, c) Asegurar la indemnización de los daños económicos asociados

27 Adoptado en Montego Bay, Jamaica, en 1982, en Torres Ugena, Nila (comp.), op. cit., nota 5 .

28 Juste Ruiz, José, El derecho internacional del medio ambiente, Madrid, McGraw-Hill, 1999, p. 75. 
al daño ambiental y, d) Asegurar la existencia de fondos para financiar dichas actividades de reparación e indemnización.

\section{La reparación del daño ambiental como consecuencia de actos no prohibidos por el derecho internacional}

Tradicionalmente se ha entendido que uno de los elementos del acto ilícito internacional es la contravención de una norma jurídica en vigor, lo que se conoce normalmente como el elemento objetivo del ilícito internacional, esto es, el incumplimiento de una norma que imponga algún tipo de obligación al destinatario.

La máxima jurídica Nullum crimen, nulla pena sine legem adquiriría, así, todo su esplendor, llegándose a afirmar por la mayoría de los autores que no existe ilícito ni, por lo tanto, responsabilidad, entendida ésta como la principal consecuencia del ilícito, si no se vulnera obligación internacional alguna.

Sin embargo, en el derecho internacional contemporáneo se va introduciendo paulatinamente la idea de la responsabilidad internacional de los Estados por actos no prohibidos por el derecho internacional pero que generan un daño y, consecuentemente, la obligación de repararlo.

La Comisión de Derecho Internacional de las Naciones Unidas trabaja en este tema, desde 1978, centrando el planteamiento de este tipo de responsabilidad en el daño producido, aunque no exista la violación de una obligación internacional a cargo del Estado responsable.

Se asemeja este tipo de responsabilidad a la responsabilidad por riesgo que existe en la mayoría de los ordenamientos jurídicos y en el principio general de que el que causa un daño a otro tiene la obligación de repararlo.

Además, y como ya hemos apuntado, este principio general se complementa en materia ambiental con otro más específico, el cual se refiere a la obligación que recae sobre los Estados de no causar contaminación más allá de sus fronteras. ${ }^{29}$

Así, cuando se produce un daño al medio ambiente de otro Estado o de zonas fuera de toda jurisdicción nacional existirá responsabilidad internacional, basada ésta en un principio general del derecho, el cual,

29 Principio 3 de la Declaración de Naciones Unidas sobre Medio Ambiente y Desarrollo, op. cit., nota 11 . 
como toda fuente formal del derecho crea, modifica o extingue derechos y obligaciones.

Como señalan diversos autores, la redacción del artículo 38 del Estatuto del Tribunal Internacional de Justicia, en la que los principios generales del derecho aparecen como fuente, al igual que los tratados y la costumbre internacional, conduce a concluir que "una demanda pueda encontrar fundamento jurídico no sólo en los tratados y la costumbre, sino también en los principios generales del derecho". ${ }^{30}$

A pesar de lo anterior, la caracterización de este tipo de responsabilidad no ha resultado tarea fácil, además de que no existe unanimidad respecto de cuáles son los principios generales del derecho y menos, todavía, cuando hablamos de principios que orientan o "sirven de referencia a la regulación de una parte del derecho o de una determinada institución jurídica". 31

En el caso de la responsabilidad internacional por actos no prohibidos por el derecho internacional, la actividad que genera el daño es una actividad lícita, no prohibida, y lo que es ilícito per se es el daño.

Existen, desde hace años, tratados internacionales específicos que prevén tipos de responsabilidad por riesgo o responsabilidad objetiva generada por determinadas actividades; el problema surge, entonces, en los casos en los que se genera un daño como consecuencia de actividades no previstas en un tratado internacional, ya que en los otros supuestos tendríamos que hablar de regímenes objetivos de responsabilidad previstos por el derecho internacional particular.

Ejemplos de este tipo de tratados son:

- Convenio sobre la Responsabilidad Civil en Materia de Energía Nuclear. ${ }^{32}$

- Convenio sobre la Responsabilidad de los Explotadores de Navíos Nucleares. ${ }^{33}$

30 Orench y del Moral, María Asunción, El derecho internacional como ordenamiento jurídico objetivo. Los principios generales del derecho internacional, Madrid, Universidad Pontificia de Comillas de Madrid, 2004, p. 166.

31 Arce y Flórez-Valdés, J., Los principios generales del derecho y su formulación constitucional, Madrid, Civitas, 1984, p. 421.

32 De 1950, http://un.org/Depts/Treaty/.

33 De 1962, http://un.org/Depts/Treaty/. 
- Convenio sobre Responsabilidad Civil por Daños Nucleares. ${ }^{34}$

- Convenio sobre la Responsabilidad Internacional por Daños Causados por Objetos Espaciales. ${ }^{35}$

- Convenio sobre Responsabilidad Civil en la Esfera del Transporte Marítimo de Sustancias Nucleares. ${ }^{36}$

- Convenio sobre la Constitución de un Fondo Internacional de Indemnización de Daños Causados por la Contaminación de Hidrocarburos. $^{37}$

- Convenio sobre Responsabilidad Civil por los Peligros de la Contaminación por Hidrocarburos Resultante de la Explotación de Recursos Minerales de los Fondos Marinos. ${ }^{38}$

- Convenio sobre la Contaminación Transfronteriza a Larga Distancia. ${ }^{39}$

- Convención de las Naciones Unidas sobre Derecho del Mar. ${ }^{40}$

Este tipo de tratados se centran en la responsabilidad civil por daños, pero todos ellos prevén la indemnización a cargo del causante de la contaminación, no la reparación del daño.

El Estado será responsable subsidiario como consecuencia de la obligación a su cargo relativa al control de que las actividades realizadas bajo su jurisdicción o control no causen daños más allá de las fronteras nacionales.

Más recientemente, los tratados relativos a la responsabilidad civil, sea ésta objetiva o subjetiva, empiezan a exigir medidas de prevención para que el daño ambiental no vuelva a producirse, además de la reparación y, en el caso de daños personales, la correspondiente indemnización.

34 De 1963, DOF del 18 de julio de 1989.

35 De 1972, DOF del 8 de agosto de 1974.

36 De 1971, http://un.org/Depts/Treaty/.

37 De 1971, DOF del 9 de agosto de 1994.

38 De 1977, http://un.org/Depts/Treaty/.

39 De 1979, http://un.org/Depts/Treaty/.

40 De 1982, op. cit., nota 27. 
Este es el caso del Convenio sobre Responsabilidad Civil por el Daño Resultante de Actividades Peligrosas para el Medio Ambiente, ${ }^{41}$ el cual sí prevé la reparación del daño ambiental.

\section{La reparación del daño ambiental como consecuencia de un crimen o delito internacional}

La Comisión de Derecho Internacional de las Naciones Unidas (en adelante CDI) trabaja desde hace tiempo en la delimitación y consecuencias de los crímenes internacionales, entendidos éstos como actos especialmente graves que vulneran obligaciones erga omnes, es decir, obligaciones hacia la comunidad internacional en su conjunto.

Dentro del artículo 19 del proyecto de artículos sobre la responsabilidad internacional del Estado, ${ }^{42}$ elaborado por la CDI, relativo a los crímenes y delitos internacionales, se establece que:

1) Un acto de un Estado que constituya una ruptura de una obligación internacional es un acto ilícito, con independencia del contenido de la obligación violada.

2) Un acto ilícito internacional que resulte de la ruptura, por parte de un Estado, de una obligación internacional de importancia esencial para la protección de intereses de toda la comunidad internacional constituye un crimen internacional.

De acuerdo al párrafo 2, inciso d), un crimen internacional puede resultar, entre otros, de una violación grave de una obligación internacional de importancia excepcional para la salvaguarda y preservación del medio ambiente humano, como las que prohíben la contaminación masiva de la atmósfera y de los mares.

Como señalan diversos autores, "el vínculo entre crímenes internacionales, obligaciones erga omnes y normas de ius cogens, ha sido obje-

41 Adoptado en Lugano, en 1993, http://www.un.org/Depts/Treaty/.

42 Proyecto de artículos sobre le responsabilidad de los Estados, aprobado en primera lectura por la Comisión de Derecho Internacional de las Naciones Unidas en su periodo de sesiones 25 (1973) a 32 (1980), en Casanova y la Rosa, Oriol, Casos y textos de derecho internacional público, 4a. ed., Madrid, Tecnos, 1990. 
to de muchas opiniones divergentes y diversos, así como de puntos de vista inconclusos". 43

Uno de los puntos centrales de este planteamiento es el que se refiere a las distintas consecuencias de crímenes y delitos internacionales. Si consideramos que los crímenes internacionales son ilícitos especialmente graves porque afectan a toda la comunidad internacional, sus consecuencias: la responsabilidad internacional y la obligación de reparar el daño causado, también deberían serlo.

En este sentido, Fitzmaurice señala que las diferencias en las consecuencias de uno y otro ilícito debieran ser: Para los crímenes, la restitución, imperiosa incluso si la carga que supone dicha restitución es desproporcionada en relación al beneficio que se obtendría en caso de indemnización. En contraste, en el caso de los delitos internacionales es necesario tomar en cuenta el criterio de la proporcionalidad. ${ }^{44}$

Aunque, como reconoce la misma autora, el artículo 42 del proyecto, que se refiere a las consecuencias de una violación grave de una obligación comprendida en el mismo, no contiene las previsiones mencionadas y la CDI adoptó, como solución, el exigir que las medidas de reparación contengan un carácter preventivo y desincentivador $\mathrm{y}$, al mismo tiempo, ha reconocido que sería erróneo creer que existe, en materia de responsabilidad internacional, un solo régimen básico aplicable a todos los hechos internacionalmente ilícitos sin distinción, y al cual se agregarían simplemente consecuencias suplementarias en caso de hechos ilícitos que constituyan crímenes internacionales.

Hay que excluir la idea de la existencia de una especie de mínimo denominador común del régimen de responsabilidad internacional. ${ }^{45} \mathrm{Sin}$ embargo, como señala Juste Ruiz, "por lo que respecta al crimen contra el medio ambiente, la práctica demuestra que la reparación de un daño ecológico de esta naturaleza es las más de las veces imposible, y que la sanción del Estado mismo requiere la puesta en marcha de mecanismos difíciles de instrumentar en el plano internacional". ${ }^{46}$

43 Citado en Fitzmaurice, M. A., "International Protection of the Environment", Recueil des Cours de l'Académie de Droit International, The Hague, Kluwer Law International, vol. 293, 2001, p. 145 (nota 359).

44 Idem.

45 Anuario CDI, 1976, http://www.un.org.

46 Juste Ruiz, José, op. cit., nota 28, p. 114. 
El artículo 42 del proyecto dispone, a pesar de lo anterior, que cada uno de los Estados lesionados (que en el caso de los crímenes internacionales serían todos o cualquiera de los Estados de la comunidad internacional) tendrá la posibilidad de solicitar que cese el comportamiento ilícito y podrá obtener del Estado que haya cometido el crimen internacional la íntegra reparación del daño.

\section{EL ESTADO DE LA CUESTIÓN EN LA UNIÓN EUROPEA}

El Libro Verde sobre la reparación del daño ecológico de $1993^{47}$ estudiaba la conveniencia de utilizar el mecanismo de la responsabilidad civil como medio para asignar la responsabilidad por los gastos necesarios en la restauración del medio ambiente $\mathrm{y}$, en segundo lugar, planteaba la posible reparación de los daños ecológicos a los que no pudiesen aplicarse los principios de la responsabilidad civil, estudiando también los sistemas de indemnización conjunta, con sus problemas y limitaciones.

Como ya habíamos mencionado, la responsabilidad civil es insuficiente para la reparación de los daños ambientales, ya que dicho mecanismo sirve para reparar los daños producidos a las personas en su salud y en sus bienes cuando forman parte del ambiente, pero es necesario que exista otro sistema para los daños causados al ambiente considerado como bien común. El bien jurídico protegido, como señalan algunos autores:

Escapa muchas veces al ámbito del derecho privado puesto que se trata de bienes públicos. Por tanto, hay que buscar soluciones novedosas e imaginativas que permitan salvar esos escollos y complementen a los seguros de responsabilidad civil. Entre las soluciones propuestas están los sistemas colectivos de cobertura ideados por la Comisión Europea en el Libro Verde, el superfondo estadounidense, que actúa de forma subsidiaria con respecto al mecanismo de responsabilidad civil y los pooles de aseguradoras y reaseguradoras. ${ }^{48}$

47 COM (93) 47 final, disponible en http://www.europa.eu.int/eur-lex/index.html/.

48 Cantalapiedra López, Óscar, "Seguros ambientales", Boletín del Ilustre Colegio de Abogados de Madrid, Madrid, 3a. época, núm. 18, mayo de 2001, p . 69. 
Como señala el Libro Verde, cuando se habla de la responsabilidad civil surge la cuestión del aseguramiento, ya que los seguros constituyen un medio de garantizar los costes de restauración.

A pesar de lo anterior, las incertidumbres que surgen en torno al daño ambiental plantean dificultades en lo que se refiere a los seguros. Es difícil que las aseguradoras cubran los daños de la contaminación. Sin embargo, en el caso de determinadas industrias y actividades que plantean riesgos excepcionales sí se ha acudido a exigirles seguros que cubran su posible responsabilidad.

La reparación del daño ambiental mediante sistemas de indemnización conjunta se plantea en el Libro Verde como una forma de asegurar la restauración de los elementos ambientales. La financiación de estos sistemas se haría con las contribuciones de los sectores económicos directamente involucrados en el tipo de daño en cuestión.

Por otra parte, en el Libro Verde se subraya que este tipo de sistema tiene las siguientes ventajas:

- Se basa en el principio quien contamina paga, ya que el coste del daño provocado por el efecto acumulado de las actividades de un sector se repartirá entre las empresas del mismo.

- Permite actuar con rapidez frente a un daño ambiental, a diferencia de la lentitud de los regímenes de responsabilidad civil.

- La carga del daño puede soportarse mejor con actividades colectivas que individuales.

Esta es, a su vez, la solución adoptada por el sistema jurídico estadounidense, que combina el mecanismo de la responsabilidad civil con un sistema colectivo de cobertura, denominado Superfund. Las tareas de descontaminación y reparación del daño ambiental dependen de la Agencia de Protección Ambiental de los Estados Unidos de América (en adelante $E P A) .{ }^{49}$ Tanto la legislación como la jurisprudencia están de acuerdo en que: Las industrias que han producido contaminación deben ser las responsables de la limpieza de los lugares que han sido contaminados como consecuencia de sus actividades y que han sido considerados por la $E P A$ o alguna otra agencia ambiental significativa como potencialmente peligrosas. Pero cuando por algunos de los motivos antes expuestos (con- 
taminación crónica, contaminación histórica o emisiones autorizadas) no es posible identificar al sujeto responsable del daño ambiental o éste es insolvente, la Ley de Responsabilidad y Respuesta Ambiental Total de $1980(C E R C L A)^{50}$ autoriza al gobierno a través de la EPA a llevar a cabo medidas urgentes de limpieza para tratar sustancias peligrosas que presenten un peligro inminente y sustancial para la salud y el bienestar, con cargo al Superfund y posteriormente la EPA repite contra los eventuales responsables. ${ }^{51}$

En abril de 2004 se aprueba en Europa la Directiva sobre Responsabilidad Medioambiental en relación con la Prevención y Reparación de los Daños Ambientales. ${ }^{52}$

En ella se señala que la rehabilitación del medio ambiente debe realizarse de manera efectiva, de modo que se cumplan todos los objetivos de la misma. Para ello, la directiva reconoce que es necesario definir un marco común para tal fin, cuya correcta aplicación debe ser supervisada por la autoridad competente. También se señala que deben establecerse disposiciones apropiadas para las situaciones en las que se hayan producido varios casos de daño ambiental, que impidan a la autoridad competente garantizar que se adopten a la vez todas las medidas reparadoras necesarias.

Sin embargo, en las situaciones en que los daños en cuestión o la amenaza de esos daños se deriven de actos que se encuentren fuera del control del operador, se sugiere que no se le exija a dicho operador que se haga cargo de las correspondientes medidas reparadoras.

En esta directiva se reconoce que el medio ambiente es un interés difuso y, por tanto, los Estados deberían garantizar que las organizaciones no gubernamentales cuyo objeto es fomentar la protección del medio ambiente pudiesen contribuir a su aplicación efectiva.

También se señala en la directiva que los Estados deberían emprender medidas para animar a los operadores a utilizar seguros $u$ otras formas de garantía financiera y fomentar el desarrollo de instrumentos y

50 Por sus siglas en inglés Comprehensive Environmental Response Compensation Liability Act, 1980.

51 Cantalapiedra López, Óscar, op. cit., nota 48, p. 58.

52 Directiva 2004/35/CE del Parlamento Europeo y del consejo, de 21 de abril de 2004, DOCE, núm. L 143 de 30-4-2004. 
mercados de garantía financiera con la finalidad de proteger de forma eficaz las obligaciones económicas que exige la directiva.

Los artículos 3o. y 4o. de la directiva precisan el ámbito de aplicación y las excepciones de la misma, señalando los supuestos a los que se aplicarán sus disposiciones y aquellos en los que no son aplicables.

El artículo 6o. se refiere específicamente a la acción reparadora que deberá llevarse a cabo cuando se hayan producido los daños ambientales. La primera exigencia que se incluye en este artículo se refiere a la información rápida a la autoridad competente de todos los aspectos pertinentes del daño ambiental con la finalidad de adoptar tanto las medidas tendentes a limitar o impedir mayores daños ambientales como las medidas reparadoras.

En cuanto a estas últimas, deberán ser definidas por los operadores que han causado el daño y sometidas a la aprobación de la autoridad competente, la cual decidirá cuáles deberán aplicarse de acuerdo a los criterios del anexo II.

Estos criterios contemplan diferentes medidas reparadoras: primarias, complementarias y compensatorias:

- La reparación primaria es toda medida reparadora que restituya o aproxime los recursos naturales y/o servicios dañados a su estado básico.

- La reparación complementaria consiste en las medidas adoptadas para compensar lo que la reparación primaria no haya restituido.

- La reparación compensatoria se refiere a las acciones adoptadas para compensar las pérdidas provisionales de recursos naturales y/o servicios que tengan lugar desde que se produjo el daño hasta el momento en que la reparación primaria haya surtido sus efectos.

En lo que se refiere a la imputación de los costes de prevención y reparación de los daños ambientales, será el operador el que cargue con ellos. En el primer caso, esto es, en el caso de los costes de prevención y control, debido al principio quien contamina paga, deberán ser cubiertos por el potencial contaminador. En el segundo de los supuestos, es decir en el caso de los costes de reparación, también recaerán sobre el causante, pero no como consecuencia del principio quien contamina paga, como señala la directiva, ya que este principio se refiere a la prevención y el control de la contaminación por lo que la reparación de los daños al am- 
biente iría más allá del principio mencionado, ${ }^{53}$ sino como consecuencia de otro principio, el que se refiere a que "todo aquel que cause un daño a otro tiene la obligación de repararlo".

Como excepciones a lo anterior, están los siguientes supuestos: ${ }^{54}$

- Cuando los daños ambientales fueron causados por un tercero.

- Cuando los daños se produjeron como consecuencia del cumplimiento de una orden o instrucción obligatoria causada por una autoridad pública.

- Cuando el daño ambiental ha sido causado por: a) Un hecho permitido mediante autorización expresa; b) Una actividad respecto de la cual se demuestre, que según el estado de los conocimientos científicos y técnicos existentes en el momento en el que tuvo lugar la actividad, no se habían considerado efectos potencialmente perjudiciales para el medio ambiente.

También se prevé la recuperación de costes por parte de las autoridades contra el operador o contra un tercero en relación con las medidas adoptadas en virtud de la directiva.

El artículo 15 se refiere a la cooperación entre los Estados miembros en el caso de un daño ambiental que afecte o pueda afectar a varios países con la finalidad de reparar dicho daño. Se hace mucho énfasis en el intercambio de información con el propósito de que los Estados afectados puedan reaccionar inmediatamente.

Aunque esta directiva contiene disposiciones detalladas tendentes a asegurar la efectiva reparación de los daños ambientales, los Estados pueden adoptar normas nacionales más estrictas.

\section{LA REPARACIÓN DEL DAÑO AMBIENTAL EN EL ORDENAMIENTO JURÍDICO MEXICANO}

\section{La reparación del daño ambiental en el derecho civil}

En México, el artículo 203 de la Ley General del Equilibrio Ecológico

53 En este sentido, García López, Tania, Quien contamina paga: principio regulador del derecho ambiental, México, Porrúa, 2001.

54 Artículo 8 de la directiva 2004/35/CE, op. cit., nota 52. 
y la Protección al Ambiente55 (en adelante LGEEPA) dispone: "Sin perjuicio de las sanciones penales o administrativas que procedan, toda persona que contamine o deteriore el ambiente o afecte los recursos naturales o la biodiversidad, será responsable y estará obligada a reparar los daños causados, de conformidad con la legislación civil aplicable".

Además, se señala en el artículo 204 que cuando por infracción a las disposiciones de la LGEEPA se hubieren ocasionado daños o perjuicios, los interesados podrán solicitar a la Semarnat, la formulación de un dictamen técnico, el cual tendrá valor de prueba, en caso de ser presentado en juicio.

La LGEEPA remite, entonces, a la legislación civil. El Código Civil Federal, ${ }^{56}$ por su parte, establece en los artículos 1910 y siguientes las normas básicas aplicables a la responsabilidad civil.

El artículo 1910 del Código Civil Federal establece: "el que obrando ilícitamente o contra las buenas costumbres cause daño a otro está obligado a repararlo, a menos que demuestre que el daño se produjo como consecuencia de culpa o negligencia inexcusable de la víctima".

Este artículo adopta el criterio de responsabilidad subjetiva ya que es necesario que el daño se produzca como consecuencia de la comisión de un ilícito. La responsabilidad objetiva se encuentra recogida en el artículo 1913 del Código Civil Federal, el cual se refiere a la responsabilidad por riesgo. Sin embargo, en ambos casos se aplicaría el artículo 1915 del mismo código, el cual dispone, en relación a la reparación del daño, que "debe consistir a elección del ofendido en el restablecimiento de la situación anterior, cuando ello sea posible, o en el pago de daños o perjuicios". De esta manera no se asegura, en la vía civil, la reparación del daño ambiental.

Como pone de relieve González Márquez, ${ }^{57}$ "la remisión que hace la legislación ambiental al derecho civil es errónea, en primer lugar, porque la responsabilidad civil sólo puede ser aplicable cuando el daño ambiental se traduce en daños a las personas o a su patrimonio, pero no es aplicable a la reparación del daño ecológico puro”.

$55 D O F$ del 28 de enero de 1988, última reforma en $D O F$ del 23 de febrero de 2005.

56 Código Civil Federal del 1o. de septiembre de 1932, DOF del 26 de marzo de 1932.

57 González Márquez, José Juan, La responsabilidad por el daño ambiental en México, México, UAM, 2002, p. 164. 
Como señala el mismo autor: "Desde la perspectiva de la reparación del daño, los sistemas jurídicos de varios países han recurrido a la adaptación del derecho civil, del derecho penal y del derecho administrativo, pero pocos son los países en los cuales se han puesto en vigor disposiciones jurídicas específicas relativas a la responsabilidad y reparación del daño ambiental". 58

Esto se ha tratado de paliar en la Ley de Responsabilidad Civil por el Daño y el Deterioro Ambiental, ${ }^{59}$ la cual todavía no sido aprobada a pesar de haber sido propuesta en 2000.

En el artículo 1o., la ley mencionada define como su objetivo regular el régimen de responsabilidad civil aplicable a las actividades con incidencia ambiental, con la finalidad de garantizar la reparación del daño.

Los artículos 8o., 90. y 10o. se refieren a la reparación del daño y el artículo 11 complementa lo anterior al señalar que la responsabilidad civil es compatible con las sanciones penales y administrativas a que dé lugar dicho daño.

La ley privilegia en todo momento la reparación de los daños al ambiente, especialmente si esos daños se han causado a bienes de dominio público o al medio ambiente general. Cuando se trata, sin embargo, de daños a particulares o a bienes propiedad del Estado la ley permite que los perjudicados acudan a las normas civiles generales.

El artículo 10 complementa lo anterior al señalar que, en caso de incompatibilidad entre dos o más reclamaciones, los órganos judiciales deberán dar preferencia a la reparación del daño.

El proyecto de ley, además de contener una legitimación activa muy amplia, lo cual no se da en la vía civil tradicional y de prever una responsabilidad objetiva, establece que la responsabilidad civil derivada de un delito o falta administrativa también se regiría por esta ley. ${ }^{60}$

Por último, cabe mencionar que existen en México regímenes especiales de responsabilidad civil como los previstos en la Ley de Responsa-

58 Ibidem, p. 116.

59 Proyecto de Ley de Responsabilidad Civil por el Daño y el Deterioro Ambiental, Gaceta Parlamentaria del 9 de noviembre de 2000.

60 Lo cual rompería con la remisión normativa establecida en leyes como la General de Vida Silvestre y la de Bioseguridad de Organismos Genéticamente Modificados. 
bilidad Civil por Daños nucleares ${ }^{61}$ o en la Ley de Navegación; ${ }^{62}$ estos instrumentos se centran en garantizar que exista un seguro para el supuesto de daños en estos sectores. No exigen, por tanto, la reparación del daño ambiental.

\section{La reparación del daño ambiental en el derecho administrativo}

En las leyes sectoriales existentes en México para la protección de algún aspecto ambiental concreto se hace referencia, también, a la cuestión de la responsabilidad del daño, pero, en algunas de ellas, aunque se alude a la necesidad de repararlo, se hace una remisión expresa a la legislación civil federal, lo cual no deja clara la cuestión.

Así, la Ley General de Vida Silvestre ${ }^{63}$ dedica varios artículos al tema de los daños y sus correspondientes medidas de restauración. El artículo 70 establece: Cuando se presenten problemas de destrucción, contaminación, degradación, desertificación o desequilibrio del hábitat de la vida silvestre, la Secretaría de Medio Ambiente y Recursos Naturales (en adelante Semarnat) formulará y ejecutará a la brevedad posible, programas de prevención, de atención de emergencias y de restauración.

Más adelante, los artículos 106 y siguientes abordan lo relativo a los daños, disponiendo que la persona que los cause estará obligada a repararlos "en los términos del Código Civil para el Distrito Federal en materia del Fuero Común y para toda la República en materia del Fuero Federal, así como en lo particularmente previsto por la presente ley y su reglamento". El artículo 108, por su parte, especifica que:

La reparación del daño para el caso de la acción de responsabilidad por daño a la vida silvestre y su hábitat, consistirá en el restablecimiento de las condiciones anteriores a la comisión de dicho daño y, en el caso de que el restablecimiento sea imposible, en el pago de una indemnización la cual se destinará, de conformidad con lo establecido en el reglamento, al desarrollo de programas, proyectos y actividades vinculados con la restauración,

61 Ley de Responsabilidad Civil por Daños Nucleares, DOF del 31 de diciembre de 1974.

62 Ley de Navegación, DOF del 4 de enero de1994; última reforma: DOF del 26 de mayo de 2000.

63 Ley General de Vida Silvestre, $D O F$ del 3 de julio de 2000; última reforma en DOF del 10 de enero de 2002. 
conservación y recuperación de especies y poblaciones, así como a la difusión, capacitación y vigilancia.

No queda muy claro, entonces, si la reparación del daño ambiental es obligatoria, o bien, si queda a elección del ofendido (que sería el único que podría iniciar la acción, de acuerdo a la legislación civil) optar por la reparación o la indemnización. En el caso de elegirse la reparación, serían aplicables los criterios del artículo 108 pero, la segunda parte de este precepto plantea serias dudas en lo que se refiere a su aplicación real.

La Ley de Bioseguridad de Organismos Genéticamente Modifica$\operatorname{dos}^{64}$ sigue la misma estructura de la anterior. Se remite, en primer lugar, al artículo 186 de la LGEEPA y, en el artículo 115 establece las medidas a adoptar en caso de "Daños o efectos adversos y significativos a la salud humana o a la diversidad biológica o a la sanidad animal, vegetal o acuícola o en caso de que se liberen accidentalmente organismos genéticamente modificados no permitidos y/o no autorizados al ambiente". Estas medidas consistirán, entre otras, en:

- La destrucción de organismos genéticamente modificados (OGM) de que se trate, a costa del interesado.

- Medidas para subsanar las irregularidades a costa del interesado.

El artículo 121 remite a la legislación civil federal, surgiendo nuevamente la duda de si dichas acciones de reparación pueden exigirse siempre que haya un daño.

Existen otras leyes que no hacen esta remisión expresa y regulan lo relativo a los daños ambientales dentro del sector concreto que cubren. Este es el caso de la Ley General de Desarrollo Forestal Sustentable ${ }^{65}$ o de la Ley General para la Prevención y Gestión Integral de Residuos. ${ }^{66}$ De forma complementaria, la legislación civil federal se aplicaría en caso de que hubiese un ofendido o lesionado por dichos daños. La diferencia, entonces, en esta segunda categoría de normas jurídicas, radica en que el daño ambiental se considera de forma autónoma, como ilícito administra-

64 Ley de Bioseguridad de Organismos Genéticamente Modificados, DOF del 18 de marzo de 2005.

65 Ley General de Desarrollo Forestal Sustentable, DOF del 25 de febrero de 2003.

66 Ley General para la Prevención y Gestión Integral de Residuos, DOF del 8 de octubre de 2003 . 
tivo y su reparación no sólo puede ser exigida por el directamente afectado, sino también por la autoridad pública correspondiente encargada de tutelar o proteger ese sector del ambiente en cuestión.

En materia forestal, la Ley General de Desarrollo Forestal Sustentable señala, dentro de sus objetivos, el restaurar los ecosistemas y recursos forestales así como los suelos contaminados.

El artículo 68 señala como causa de revocación de las autorizaciones de aprovechamiento forestal el que no se apliquen las medidas de restauración que la Semarnat haya decretado en la superficie objeto de la autorización. El artículo 127, en el mismo sentido, añade: "los propietarios, poseedores, usufructuarios o usuarios de terrenos forestales o preferentemente forestales están obligados a realizar las acciones de restauración y conservación pertinentes y aquellas que para tal caso dicte la secretaría". El artículo 136 prevé la exigencia de una indemnización económica a cargo del responsable pero, más adelante, el artículo 167 agrega: "Cuando la Semarnat determine, a través de las visitas de inspección, que existen daños al ecosistema, impondrá como sanción mínima al responsable la ejecución de las medidas de restauración correspondientes".

En materia de residuos, la Ley General para la Prevención y Gestión Integral de los Residuos incluye dentro de los principios rectores en la materia el de que "corresponde a quien genere residuos... la reparación del daño". ${ }^{67}$ El artículo 68 incorpora: "Quienes resulten responsables de la contaminación de un sitio, así como de daños a la salud como consecuencia de ésta estarán obligados a reparar el daño causado, conforme a las disposiciones legales correspondientes"

En lo que se refiere a materiales y residuos peligrosos, la LGEEPA exige claramente la reparación del daño al establecer: Cuando la generación, manejo o disposición final de materiales o residuos peligrosos, produzca contaminación del suelo, los responsables de dichas operaciones deberán llevar a cabo las acciones necesarias para recuperar y restablecer las condiciones del mismo, con el propósito de que éste puede ser dedicado a alguna de las actividades en el programa de desarrollo urbano o de ordenamiento ecológico que resulte aplicable, para el predio o zona respectiva. ${ }^{68}$

68 Artículo 152 bis de la LGEEPA. 
Del mismo modo, el artículo 153, fracción VII, cuando se refiere a la importación o exportación de materiales o residuos peligrosos, dispone: El otorgamiento de autorizaciones por parte de la Semarnat para la importación o exportación de materiales o residuos peligrosos quedará sujeto a que se garantice debidamente la reparación de los daños y perjuicios que pudieran causarse tanto en el territorio nacional como en el extranjero.

Por su parte, el Reglamento de la LGEEPA en Materia de Residuos Peligrosos 69 establece en su artículo 42 la posibilidad de que la Semarnat dicte, promueva y aplique las medidas de seguridad que procedan cuando "por cualquier causa se produzcan derrames, infiltraciones, descargas o vertidos de residuos peligrosos durante cualesquiera de las operaciones que comprende su manejo".

Dentro del aviso que, de acuerdo a este artículo, el generador debe entregar a la Semarnat se exige que se describan claramente las medidas adoptadas para la limpieza y restauración de la zona afectada.

El capítulo IV del reglamento, relativo a la importación y exportación de residuos peligrosos, exige, como requisito previo al otorgamiento de la autorización de importación o exportación, el otorgamiento de seguros, fianzas o depósitos para garantizar, entre otros, la reparación de los daños que pudieran causarse.

\section{La reparación del daño ambiental en el derecho penal}

El título vigésimo quinto del Código Penal Federal ${ }^{70}$ tipifica los delitos ambientales y prevé sanciones pecuniarias e incluso privativas de libertad para algunos de ellos. Además, el artículo 421 establece que el juez puede imponer penas como: la realización de acciones tendentes a restaurar el statu quo ante o la reincorporación de los elementos naturales sustraídos.

Estas sanciones, que pretenden la reparación del daño ambiental, quedan a criterio de cada juez y son complementarias a las sanciones pecuniarias y privativas de libertad mencionadas.

69 Reglamento de la LGEEPA en materia de residuos peligrosos, DOF del 25 de noviembre de 1988.

70 Código Penal para el Distrito Federal en Materia Común y para toda la República en Materia Federal, DOF del 14 de agosto de 1931. 


\section{CONCLUSIONES}

Como podemos observar, tanto a nivel internacional como nacional, la reparación efectiva de los daños ambientales está lejos de ser una tónica general y tan sólo en el sistema estadounidense y en el europeo se han hecho los esfuerzos necesarios para garantizar que, pese a las dificultades de la "reparación in natura", básicamente económicas, el medio ambiente regrese a un estado aceptable tras la existencia de un daño.

En el ámbito internacional, aunque el régimen tradicional de responsabilidad se centra en la reparación del daño, éste se estructura bajo la óptica de las lesiones personales, patrimoniales y económicas, dejando a un lado el concepto de daño ecológico puro.

Existen numerosos tratados internacionales que establecen la responsabilidad civil por daños, incluidos los daños al ambiente, sin embargo, la mayoría de estos regímenes se centran en asegurar la consecuente indemnización a cargo del causante, sin exigir, en todos los casos, la reparación del daño ambiental.

En la Unión Europea, la responsabilidad civil por daños al ambiente se utiliza como un mecanismo para asegurar la restauración del medio ambiente en caso de daños y se están ideando soluciones que permitan aplicar los principios de la responsabilidad civil a los daños ambientales, considerando los elementos naturales como bienes públicos.

En México, el derecho civil no asegura la reparación de los daños ambientales ya que existe la opción, dada por el artículo 1915, de que el ofendido elija entre la correspondiente indemnización o la restauración de los elementos dañados. Esto se está intentando paliar con la propuesta de Ley de Responsabilidad Civil por el Daño y el Deterioro Ambiental, la cual se discute desde 2000 sin haber sido todavía aprobada. Esta propuesta tiene como objetivo central, precisamente, el garantizar la reparación del daño, además de ampliar considerablemente la legitimación activa en caso de daño ambiental, al considerar el medio ambiente como un interés difuso.

En materia administrativa sí se contempla en México la reparación del daño ambiental, pero la mayoría de las normas jurídicas hacen una remisión al derecho civil por lo que no queda claro si las medidas de reparación son obligatorias o sólo se aplicarían cuando se elige esta opción en lugar de la indemnización. 
Por último, en materia penal también se prevé la restauración de los elementos ambientales, aunque queda a elección del juez el exigir dicha reparación como una sanción más consecuencia de un ilícito en materia ambiental.

\section{BIBLIOGRAFÍA}

\section{Libros}

ARCE Y FLÓREZ-VALDÉS, J., Los principios generales del derecho y su formulación constitucional, Madrid, Civitas, 1984.

BeCERra Ramírez, Manuel, Derecho internacional público, México, McGraw-Hill, 1997.

Bowman, Michael y Boyle, Alan (ed.), Environmental Damage in International and Comparative Law. Problems of Definition and Valuation, Oxford, Oxford University Press, 2002.

CAMPOS DÍAZ BARRIGA, Mercedes, La responsabilidad civil por daños al medio ambiente. El caso del agua en México, México, UNAM, 2000.

Casanova y la Rosa, Oriol, Casos y textos de derecho internacional público, 4a. ed., Madrid, Tecnos, 1990.

Fitzmaurice, M. A., "International Protection of the Environment", Recueil des Cours de l'Académie de Droit International, The Hague, Kluwer Law International, 2001, vol. 293.

GARCÍA LÓPEZ, Tania, Quien contamina paga: principio regulador del derecho ambiental, México, Porrúa, 2001.

GonzÁlez MÁRQuez, José Juan, La responsabilidad por el daño ambiental en México, México, UAM, 2002.

Jurisprudencia sobre medio ambiente, Madrid, Ministerio de Medio Ambiente, 1996.

Juste RUIZ, José, El derecho internacional del medio ambiente, Madrid, McGraw-Hill, 1999.

KISS, Alexandre y SHELton, Dinah, International Environmental Law, Nueva York, Transnational Publishers, Inc., 1991.

LOPERENA ROTA, Demetrio, Los principios del derecho ambiental, Madrid, Civitas, 1998.

LÓPEZ BASSOLS, Hermilo, Derecho internacional público contemporáneo e instrumentos básicos, México, Porrúa, 2001. 
Miguel Perales, Carlos de, La responsabilidad civil por daños al medio ambiente, Madrid, Civitas, 1994.

ORENCH Y DEL MORAL, María Asunción, El derecho internacional como ordenamiento jurídico objetivo. Los principios generales del derecho internacional, Madrid, Universidad Pontificia de Comillas de Madrid, 2004.

RODRÍGUEZ CARRIÓN, Alejandro J., Lecciones de derecho internacional público, Madrid, Tecnos, 2002.

SEARA VÁZQUeZ, Modesto, Derecho internacional público, 5a. ed., México, 1983.

SepúlvedA, César, Derecho internacional, 18a. ed., México, Porrúa, 1997.

TORRES UgENA, Nila (comp.), Textos normativos de derecho internacional público, 5a. ed., Madrid, Civitas, 1996.

\section{Legislación}

Código Civil Federal, DOF, del 26 de marzo de 1932.

Código Penal para el Distrito Federal en Materia de Fuero Común y para toda la República en Materia de Fuero Federal, DOF, del 14 de agosto de 1931.

Comprehensive Environmental Response Compensation and Liability Act, 1980.

Directiva 2004/35/CE del Parlamento Europeo y del Consejo del 21 de abril de 2004, DOCE, núm. L 143 del 30 de abril de 2004.

Ley de Bioseguridad de Organismos Genéticamente Modificados, DOF, del 18 de marzo de 2005.

Ley General de Desarrollo Forestal Sustentable, DOF, del 25 de febrero de 2003.

Ley General de Vida Silvestre, $D O F$, del 3 de julio de 2000. Última reforma $D O F$, del 10 de enero de 2002.

Ley General del Equilibrio Ecológico y la Protección al Ambiente, DOF, del 28 de enero de 1988. Última reforma, $D O F$, del 23 de febrero de 2005.

Ley General para la Prevención y Gestión Integral de Residuos, DOF, del 8 de octubre de 2003.

Ley de Navegación, $D O F$, del 4 de enero de 1994. Última reforma, $D O F$, del 26 de mayo de 2000. 
Ley de Responsabilidad Civil por Daños Nucleares, DOF, del 31 de diciembre de 1974.

Proyecto de Ley de Responsabilidad Civil por el Daño y el Deterioro Ambiental, Gaceta Parlamentaria, 9 de noviembre de 2000.

Reglamento de la LGEEPA en Materia de Residuos Peligrosos, DOF, del 25 de noviembre de 1988.

\section{Tratados y documentos internacionales}

Convenio de Basilea sobre Movimientos Transfronterizos de Desechos Peligrosos y su Eliminación, Basilea 1989, Protocolo 1999, http://un. org/Depts/Treaty/.

Convenio de Londres sobre la Prevención de la Contaminación del Mar por Vertimiento de Desechos y otras Materias, Londres, 1972, http:// un.org/Depts/Treaty/.

Convenio de Naciones Unidas sobre Derecho del Mar, Montego Bay, 1982, http://un.org/Depts/Treaty/.

Convenio de Nairobi para la Protección, la Ordenación y el Desarrollo del Medio Marino y Costero de la Región de África Oriental, Nairobi, 1985, http://un.org/Depts/Treaty/.

Convenio para la Protección del Medio Marino en la Zona del Mar Báltico, Helsinki, 1974, http://un.org/Depts/Treaty/.

Convenio sobre la Constitución de un Fondo Internacional de Indemnización de Daños causados por la Contaminación de Hidrocarburos de 1971, http://un.org/Depts/Treaty/.

Convenio sobre la Contaminación Transfronteriza a Larga Distancia de 1979, http://un.org/Depts/Treaty/.

Convenio sobre la Responsabilidad Civil en la Esfera del Transporte

Marítimo de Sustancias Nucleares de 1971, http://un.org/Depts/ Treaty/.

Convenio sobre la Responsabilidad Civil en Materia de Energía Nuclear de 1950, http://un.org/Depts/Treaty/.

Convenio sobre la Responsabilidad Civil por Daños Nucleares de 1963, http://un.org/Depts/Treaty/.

Convenio sobre la Responsabilidad Civil por los Peligros de la Contaminación por Hidrocarburos Resultantes de la Explotación de Recursos Minerales de los Fondos Marinos de 1977, http://un.org/Depts/ Treaty/. 
Convenio sobre la Responsabilidad de los Exportadores de Navíos Nucleares de 1962, http://un.org/Depts/Treaty/.

Convenio sobre la Responsabilidad Internacional por Daños Causados por Objetos Espaciales de 1972, http://un.org/Depts/Treaty/.

Convenio sobre Responsabilidad Civil por Daños Resultantes de Actividades Peligrosas para el Medio Ambiente, Lugano, 1993. http://un. org/Depts/Treaty/.

Convenio sobre Responsabilidad y Compensación de Daños Producidos por el Transporte de Sustancias Peligrosas y Nocivas por el Mar, 1996, http://un.org/Depts/Treaty/.

Declaración final de la Conferencia de las Naciones Unidas sobre el Medio Humano, Estocolmo, Suecia, 1972, http://www.unep.org.

Declaración final de la Conferencia de las Naciones Unidas sobre Medio Ambiente y Desarrollo, Río de Janeiro, Brasil, 1992,http://www.un. org/esa/sustdev/documents/agenda21/index.htm .

Declaración final de la Conferencia de Naciones Unidas sobre Desarrollo Sostenible, Johannesburgo, Sudáfrica, 2002, http://www.un.org/esa/ sustdev/documents/WSSD_POI_PD/Spanish/WSSDsp_PD.htm

Proyecto de Artículos sobre la Responsabilidad Internacional de los Estados por Hechos Internacionalmente Ilícitos, 2001, http://www. un. org/docs/. 